\title{
Is the patient's age contraindication to thyroid surgery? R Lucchini ${ }^{1}$, A Sanguinetti ${ }^{2}$, F Calzolari*1, M d'Ajello' ${ }^{1}$, F d'Ajello', M Monacelli ${ }^{1}$ and $\mathrm{N}$ Avenia ${ }^{1}$
}

\author{
Address: ${ }^{1}$ Struttura Complessa Di Endocrinochirururgia del Collo e dei Tessuti Molli, Azienda Ospedaliera "Santa Maria" Terni, Italy and ${ }^{2}$ Struttura \\ Dipartimentale di Senologia Azienda Ospedaliera "Santa Maria" Terni, Italy \\ * Corresponding author
}

from XXI Annual Meeting of The Italian Society of Geriatric Surgery

Terni, Italy. 4-6 December 2008

Published: I April 2009

BMC Geriatrics 2009, 9(Suppl I):A72 doi:10.1 186/I47|-23 |8-9-SI-A72

This abstract is available from: http://www.biomedcentral.com/I47I-23I8/9/SI/A72

(c) 2009 Lucchini et al; licensee BioMed Central Ltd.

\section{Background}

There is increased risk of surgical treatment in elderly patients, but little has been written on the safety and efficacy of thyroid surgery in this group.

\section{Objective}

To determine if there is an increased risk of morbidity and mortality of thyroid surgery in patients over 75 years old.

\section{Patients and methods}

During the period 2005-2007, 702 patients aged 50 and over underwent procedures by two surgeons in our Unit. We retrospectively compared indications for surgery, procedures, pathology complications and mortality in three groups: 50-60-year-olds (234 patients), 61-74-year-olds (312 patients) and those aged 75 years and over (44 patients).

\section{Results}

The main indication for surgery in all three groups was compression or risk of malignancy. Total thyroidectomy was the main procedure performed. Although benign multinodular goitre was the commonest diagnosis, the over 75-year-olds had fewer benign multinodular goitres than the 61-74 group and more malignancy than the other two groups. There was no significant difference in mortality between the three groups.

\section{Conclusion}

Surgery in patients over 75 is as safe as in younger patients with no increase in morbidity and mortality. Benign multinodular goitre is the most common indication for surgery. 